\title{
Problems and Countermeasures of Female Career Development in Taiwan-funded Enterprises--Taking Huaian's Taiwan-funded Enterprises as an Example
}

\author{
Shuxian Liu \\ School of International College National Institute of Development Administration \\ 543446219@qq.com
}

Keywords:Taiwan-funded enterprises, female, career development, suggestions

\begin{abstract}
This study takes the female workers of Taiwan-funded enterprises in mainland as the research subject, through a special study female career development of Taiwan-funded enterprises in mainland, to understand the differences between them, and then summarize the existence of self-cognition of Taiwan-funded enterprises in the development of female occupation pessimistic, active participation in management awareness, management ability is not strong and so on. This paper puts forward the following strategies and suggestions, such as correct understanding of themselves, establishment of a correct outlook on career, maintaining a good mindset, and dealing with the relationship between family and work scientifically.
\end{abstract}

\section{Introduction}

With the continuous development of economy, the overall situation of female career development in Taiwan-funded enterprises has been greatly improved, and there are more opportunities for female to display their leadership ability, a large number of female friends take up leading positions. Female managers have a stronger sense of initiative and positive, and they are good at comprehensive analysis of relevant information, willing to integrate into the organization actively, At the same time, they are inclined to communicate with colleagues fully, grasp the situation more carefully, and show their unique personality of understanding, delicacy and affinity; they gradually improve their quality by learning, observing and participating in organized activities. Through their own special endeavor, help, guide and the excellent performance in the work unit, these female workers encourage and influence more women to strive to develop upwards. However, due to the impact of the social background, traditional customs, politics, culture and others, there are still some problems of women's career development in Taiwan-funded enterprises, which means that we must pay attention to this point.

\section{The problems of female career development in Taiwan-funded enterprises:}

\subsection{The pessimism of self-perception}

Because of their living environments, and Taiwan-funded enterprise female often lack correct self-cognition, the female tend to have a more severe inferiority complex. Therefore, the "men outside the home, women inside" point of view from the formation of trivial housework should be borne by women has become the unalterable truth. The main time and energy of women should be used to take care of the family, give parents more care, give her husband more love, and give children more concern. Women can't give up the family responsibility for their future, and they have to dedicate themselves to their children's growth and their husband's career. It is generally believed that if the husband is with a bright future, she has a backer; and if their children are well cultivated, they are in prospect. However, the long-term inferiority, lack of self-confidence and lack of expectations to their own ability often lead to the loss of their enthusiasm and morale, resulting in their lazy personality, which may exacerbate their negative inferiority complex. 


\subsection{The gender discrimination under social conventions}

Although the social development has already gone through the patriarchal era, influenced by the old customs, the impression of gender is always stereotyped. People tend to use the proverb of "being a good wife and a kind mother" to describe women. Leaders must be male, and only men are resolute, courageous and independent, which is in line with public expectations. Women are born to contribute to their families, who are synonymous with weakness. The Taiwan-funded enterprises women are not good at challenging management posts. If there is a woman who has taken up a leading position by hard work, or has made some achievements in career, she will be called the nickname of "tough girl ". In the Department, for the male, if their leader is a woman, then he will have a psychological conflict, and is unwilling to accept women's leadership and restraint. In the work, whether the leader is correct or not, the male are not willing to cooperate in their deep heart. This kind of invisible sexism is undoubtedly a wrong interpretation to women's ability, which is also a kind of depreciation to women's management ability. This gender discrimination, to some extent, weakens or even destroys women's self-confidence, enthusiasm and their pursuit of progress; it restricts the development of women's innovative work and the improvement of their self-ability, and it also affects the realization of enterprises' organizational goals.

\subsection{The entanglement of family concept in the conflict between tradition and civilization}

With the continuous progress of society, the concept of equality between men and women has been deeply rooted in the hearts of the people, and women's self-awareness has gradually increased. Most women expect to go out of the family, go to the society, go into the workplace actively, and compete with men to realize their own values. However, the accumulation of thousands of years of historical tradition, male chauvinism and family centered theory in China has seriously troubled women in the Taiwan-funded enterprises. The duality of work and family roles, like two big mountains, makes them gasp for breath, which makes them feel powerless and miserable. The more work they spend, the less attention they have to their children and husbands, which often gives them a sense of guilt that they can't get rid of. In this way, on the one hand, women want to develop their own career through their own struggle, get rid of men's asylum, and realize their life value; on the other hand, they cannot get rid of the influence of traditional culture and the suppression of gender role responsibility; women will consciously or unconsciously assume the division of labor formed by history, which is to put the family in the first place. This outdated and backward gender concept also brings negative energy to men, which means that when their wives spend more time or energy on their work, they are often unable to accept it; moreover, if the female leaders in the department are doing well, men tend to evaluate them with a contemptuous eye and a resistance attitude. The mainstream social environment of masculinity and the traditional gender division of labor limit the development of women's ability, which affects women's efforts in the workplace.

\subsection{The weakness of the consciousness of active participation in management and the weakness of the management ability}

It has been thirty or forty years since the implementation of the policy of Reform and Opening-up, but the awareness of women's participation in management is still weak. Although women's educational background may be very high in the Taiwan-funded enterprises, many women still have the traditional concept that is "male is strong and female is weak", which leads to their sense of participation in department management is not strong. They always think that taking part in family affairs is the main battlefield of women, and they can only act as a supporting role in their careers. When a department lacks a person responsible for the recruitment of qualified employees, most of the time, the male registration is more, while the female is not active, and even registration is also very few. 


\section{Some suggestions to promote the female career development in enterprises}

\section{1 keep a good mindset and understand themselves correctly}

Good mentality and healthy psychology are the basic conditions for female friends to go into management positions. In the process of occupation development, women not only have to bear the pressure from the job itself, but also are restricted by the traditional patriarchal concept in China. Traditional concepts make them develop the mind of anxiety, psychological inferiority and cowardice. The social atmosphere of "male outside and female inside ", "assist husband and bring up children" has hindered the development of women's occupation. Working hard and taking care of the family is a very difficult thing to balance. If Taiwan-funded enterprises female want to succeed in the workplace, they must withstand the pressure, do not care about other people's evaluation, and do not care about the groundless talk in society. Women should maintain a positive and good attitude, boldly go out of the family, bravely enter the society, and use their own strength to win the opportunity of their own career development.

Of course, Confucius and his disciples have said that if you know the enemy and know yourself, and you can fight a hundred battles with no danger of defeat. If a person wants to succeed, they must have a correct and all-round understanding of themselves, know their strengths and weaknesses, and combine their own personality characteristics; at the same time, they must adjust measures to local conditions and make proper orientation. The Taiwan-funded enterprises Female need to make best use of the advantages and bypass the disadvantages, through their careful and gentle, affinity characteristics, in order to realize the ambition and to establish and maintain the strong business platform.

\subsection{Set up correct career view and deal with the relationship between family and work scientifically}

Everyone has his or her own professional ideas, especially women. Before we get into the management position, we may be timid because of the new position, but we must know ourselves correctly, dare to learn new knowledge, familiarize ourselves with the new business as soon as possible, change the role of our post, and learn to deal with the relationship between colleagues. At the same time, male should understand and support women in management positions. Male compatriots need to understand women from the perspective of women, rather than using male standards to demand women. Male colleagues, especially leaders, should give support to women's work, which means that they should take a correct attitude towards women's acting styles such as delicacy, pursuit of perfection and initiative to create a harmonious atmosphere. Men should help female friends choose a correct career path. The Taiwan-funded enterprises female will encounter the contradiction between family and work in the process of management, which will cause psychological pressure on them. How to deal with the relationship between family and work often troubles many women who are in management positions; it's a tough choice for a woman. When this happens, The Taiwan-funded enterprises female often stop working and turn back to the traditional way that is to assist husband and to bring up children. We don't encourage women to give up their families and treat work as the first thing; but the Taiwan-funded enterprises female can deal with the relationship between family and work scientifically, arrange the family and work reasonably, strive for the support of family members, and improve their work efficiency. Leaders should also provide policy support, such as consciously creating a stable and harmonious working environment and creating good interpersonal relationship for them. Let women have a sense of ownership and give the platform for female to play their talents.

\subsection{Purify the social environment and create correct public opinion guidance}

In society, the concept of "men outside, women inside" is common, which means that women have to depend on men. If we want to realize the equality between men and women, we must abandon the backward gender concept, purify the social environment, strive to carry forward the advanced gender consciousness, and use the correct direction of public opinion to influence people's 
thought. In order to select and cultivate female cadres, we should break the interference of the traditional feudal ideology, improve the political status of women, stimulate the enthusiasm of women's participation in management, and actively select more women for leading positions. There are many successful cases of women's active participation in government and political affairs in the society, which has more or less influence on women's change of their ideas and emancipation of their minds. Many women are more liberated and more confident. Women entrepreneurs such as Dong Mingzhu show women's unique style in management positions. We should also vigorously publicize the successful deeds of successful women, protect the legitimate rights and interests of women, and increase the training of female managers. And we should let more people pay attention to the selection and training of female managers, create a relaxed workplace environment for female friends, and promote the rapid growth of women.

\subsection{Set up necessary education, training and incentive mechanism}

Faced with the increasingly fierce competition for talents, the enterprise leaders should change their management concept. It is an important and effective way to improve the core competitiveness of enterprises to strengthen the education and training of female managers. The training for managers, especially for female managers, should not be regarded as a burden. The training of female managers should not be regarded as dispensable. To improve the quality of managers and professional skills is a shortcut to improve the efficiency of enterprises. Of course, the education and training of female employees need specific analysis of specific issues. According to the existing or possible problems that are faced by the female friends may face in the management, we should draw up the practical and targeted education and training programs. Especially the time and manner of education and training should be flexible. We should not only affect the daily management work, but also take into account the needs of the female family, as far as possible not to occupy women's spare time. Only by improving the quality of female managers, improving management skills and improving the management level, can we truly realize the benefits of management.

The Taiwan-funded enterprises leaders should start from the basic needs of human resources career, and create an atmosphere of wanting to learn and loving to learn. We should make the necessary incentive mechanism, mobilize the initiative and the Taiwan-funded enterprises of female managers to the greatest extent, and stimulate the enthusiasm of female managers. Let women managers actively improve their management ability, improve their comprehensive quality, and stimulate their own potential. Leaders should use a variety of incentive policies to closely link the development of enterprises with the personal interests of the individual, and enhance the sense of responsibility and mission of female managers, so that women managers can want to work and do their own jobs. In this way, it will be twice the result with half the effort.

\section{References}

[1] Chen Weijuan. Research on female leadership of Chinese enterprises [D]. Changchun: Changchun University of Science and Technology, 2010.

[2] Shi Jiehui. Research on female leadership traits, team climate and employee performance [D]. Beijing: University of International Business and Economics, 2015.

[3] Xu Jianxin. Corporate culture management of Taiwan funded enterprises in mainland China [J]. Journal of Jiangsu Radio and TV University, 2009 (06) 81 - 83.

[4] Dai Xinting. The research of female leadership development from the perspective of flexible leadership [D]. Liaoning, Liaoning Normal University, 2015. 